\title{
VAGABUNDOS E MALANDROS: APONTAMENTOS E APROXIMAÇÕES ENTRE AS NARRATIVAS DE MÁXIMO GÓRKI E JOÃO ANTÔNIO
}

\author{
Carlos Alberto Farias de Azevêdo Filho \\ Professor do Curso de Comunicação da UEPB. \\ Doutorando em Letras na Unesp/Assis e Bolsista do CNPq.
}

\section{RESUMO}

Propomos aqui uma comparação da representação do vagabundo na obra do escritor russo Máximo Gorki (1868-1936) com a dos malandros nos contos do brasileiro João Antônio (1937-1996). Nossa hipótese é a da influência da literatura russa na construção da narrativa curta em João Antônio, dada a uma continuidade da tradição realista na literatura mundial. Assim, comparamos dois importantes livros dos escritores: $O S$ Vagabundos- Malva- Tchelkache- Konovalov (de M. Gorki) e Malagueta, Perus e Bacanaço (de João Antônio)

\author{
Breve rebentará a tempestade! \\ Esse corajoso albatroz \\ Paira altivo entre os raios \\ E sobre o mar furiosamente urrando \\ Então grita o profeta da Vitória: \\ QUE MAIS FORTE ARREBENTE \\ MAIS FORTE A TEMPESTADE! \\ (Poema de Máximo Gorki)
}

A primeira vista o que aproxima o contista brasileiro João Antônio (1937-1996) do escritor Máximo Gorki (1868-1936)? Nascido um ano após o falecimento do escritor russo, João Antônio é uma espécie de continuador de uma tradição realista que se preocupa com a injustiça social e ao mesmo tempo traz, à maneira de Gorki, um amor aos mais simples.

Assim, pretendemos analisar nestas notas, na forma de apontamentos livres e imprecisos, a representação dos excluídos, em especial a construção da imagem dos vagabundos gorkianos e joaoantonianos, ambos presentes na primeira fase dos escritores russo e brasileiro. Propomos uma breve comparação entre os livros $O s$ Vagabundos (Malva, Tchelkache e Konovalov), de Máximo Górki e Malagueta, Perus e Bacanaço (de João Antônio), publicado no Brasil pela Civilização Brasileira em 1963. 


\section{0-Pistas de Leituras?}

Em seu trabalho de doutoramento em Letras na Universidade de São Paulo (USP), sob o título de $O$ conto na obra de João Antônio: uma poética da exclusão, Clara Ávila Ornelas levanta uma hipótese curiosa. Ela sustenta que as obras de Dostoiévski, Tchekhov e Gorki são importantes para a formação e no pensamento de João Antônio. Assim como o escritor paulista, "grande parte destes exerceu o ofício de jornalismo e da literatura (...)" (p.169). A pesquisadora assinala que na biblioteca particular de João Antônio existem sete obras de Górki, "sendo três romances Adolescência, A Mãe e O Espião; e três coletâneas de contos: Os melhores contos de Máximo de Górki, Antologia do Conto Russo, Vol.VII e Vagabundo Original, sendo este último possui mais grifos de leitura" (p.59).

Outro encontro entre Górki e João Antônio, ainda segundo a pesquisa de Ornelas, é "a representação da vida dos excluídos socialmente e a crítica dos falsos valores burgueses" (p.60). Além disso, a pesquisadora mostra também que ambos vivenciaram muito do que escreveram em suas produções.

\section{0-O bossiak gorkiano e o malandro de João Antônio}

No prefácio ao livro Vagabundos, obra publicada no Brasil em 1965, o escritor e jornalista Carlos Heitor Cony afirma que:

Os vagabundos ocupam, na obra de Górki, uma posição explicativa: Górki criou, literariamente, o vagabundo. Não se pode associa-lo aos nomes de Hansum, ou de Dickens, ou de Vitor Hugo. O vagabundo de Górki é um tipo a parte: o bossiak, um equivalente ao eslavo do clochard francês. Foi o exostimo do tipo que chamou a atenção para o jovem autor. Introduzia-se na literatura, um novo mundo,uma nova visão das coisas.

Não se admira que tal admiração se dê também na estréia literária de João Antônio,em 1963, com Malagueta, Perus e Bacanaço. O então diretor editorial da Civilização Brasileira, o crítico Mário da Silva Brito vai escrever na orelha da primeira edição do livro o texto Os malandros paulistas entram na literatura. Vale transcrever um trecho: 
João Antônio não levanta personagens pitorescas, engraçada, anedóticas nem as suas histórias são amenas, humorísticas, de mero entretenimento. Sua gente é típica, mas nada caricatural. É universal, vincada de realismo e verdade, possui sua própria valência, seu peso específico Surge do proletariado, da pequena burguesia fronteira da pobreza e são as lutas, revoltas, frustrações e sonhos desse povo que o autor interpreta ou sustenta em contos onde os heróis são tratados como almas vivas, como pessoas humanas sofridas e desvalidas, espezinhadas e perseguidas, desoladas e triste, líricas e cruéis.

Poeta dos malandros e dos pobres-diabos, perquiridor dos sentimentos desalentados e deste descontentamento indefinível que marca dramaticamente o homem moderno, João Antônio traz para as letras brasileiras uma contribuição nova e firma-se, de ponto, como um valor que acrescenta a literatura de uma visão original, personalíssima, séria e fecunda.

Voltando a Górki, Carlos Heitor Cony vai ainda afirmar que Máximo Gorki criou literariamente o bossiak como um elemento que nem era o camponês medieval da Rússia czarista nem da nobreza que compunha o regime como classe dirigente. Opostos como lobo e cordeiro, nobres e camponeses, vão desempenhar papéis históricos opostos na história da derrubada do regime czarista e do episódio de construção da primeira república socialista do mundo.

O bossiak gorkiano vai se situar distante do santo e ingênuo mujique (camponês). Górki vai construir literariamente o bossiak como sendo um tipo literário que se coloca em oposição ao camponês. O bossiak é um excluído, um fora da lei, um bandido.

No famoso texto de 1912, Como aprendi a escrever( Porto Alegre: Mercado Aberto, 1984), uma espécie de testamento literário do autor russo, escrito na maturidade e publicado na década de 30, ele tenta explicar a pergunta, feita por jovens, indagando por que ele escrevia sobre vagabundos. No prefácio do livro, escrito pelo tradutor Charles Kiefer, intitulado As Dimensões de Máximo Górki ,afirma-se que a literatura do autor russo era fruto das experiências de vida pois Górki "convive com ciganos, 
pescadores, trabalha como estivador, come e dorme entre os vagabundos do porto de Odessa" (p.5)

Balanço de sua própria obra literária e de sua formação como leitor, Como aprendi a escrever vai relatar o tributo do russo a outros grandes escritores de seu país e do estrangeiro, dentre os quais Stendhal, Balzac, Flaubert, Dickens, Dostoievski, Turgueniev, Tolstoi, Gogol, Leskov, Tchecov entre outros. Para Górki, literatura e vida se relacionam a partir da constatação de que a observação da realidade é material para o escritor construir seu texto, acrescendo-o de imaginação e espírito.

Deixemos Gorki explicar a predileção por vagabundos na sua obra:

Os vagabundos eram para mim "homens extraordinários" por serem "desclassificados", homens que haviam se separado de seu meio ou haviam sido repudiados por el, e que,devido a isto, tinham perdido os traços mais característicos de sua classe (...) em Kazan, na fábrica de vidro, encontrei-me com outro grupo de umas vinte pessoas (...) a maioria deles era de enfermos e bêbados;as brigas eram freqüentes entre eles, porém estavam ligados por laços de camaradagem, de ajuda mútua, extremamente desenvolvidos, e tudo o que conseguiam ganhar ou roubar comiam e bebiam em comum (...)De forma que eu posso dizer que minha predileção pelos vagabundos nasceu de meu desejo de retratar pessoas ao invés dos mesquinhos tipos pequenoburgueses (p.37-39)

O crítico literário Otto Maria Carpeux considera M. Górki uma espécie de Colombo literário ao descobrir um novo mundo-a vida dos vagabundos da Rússia:

Os personagens de Górki eram outros: os vagabundos, os mendigos, os desempregados, os criminosos, os nômades que erravam pelas imensas estepes do imenso império russo, de cidade para cidade, pedindo trabalho ou pedindo esmola, um verdadeiro lumpenproletariat, de costumes e de fala pitorescos e como pitorescos eles fascinavam os leitores russos. (p.11)

O professor e tradutor Boris Schnaiderman também enfatiza que Gorki faz uma opção de retratar literariamente os vagabundos em sua obra: 
(...) se existe algo de muito importante a extrair dos livros de Górki, é uma lição humana, de sinceridade que raia, às vezes, ao desespero, de afeto desmedido pelo semelhante, de uma entrega de toda a personalidade à busca da verdade e da justiça (...) Os primeiros (contos) refletem, sobretudo os ambientes que ele conheceu nas andanças pelas estradas intermináveis da Rússia, o submundo de prostitutas, mendigos e ladrões, a humanidade torva das casas de cômodos e dos albergues noturnos, as "universidades" a que se referia com tão profundo sentido humano em sua autobiografia. (p.912)

Na obra Historia de la literatura rusa, Alexander Brückner ressalta que a obra de Górki situa-se no contexto dos escritores da última década do século 19, sendo marcada por uma permanente busca de representar a "pequena gente" do seu lugar e sua infinidade de tipos. Ao representar o vagabundo, na visão do autor, Górki tenta uma volta ao estado natural, na qual as personagens confiam na sua própria força para se libertar de todo jugo. O vagabundo gorkiano é uma espécie de homem que tenta superar as barreiras, os lugares e a ética. Brückner afirma que Górki tem uma vasta galeria de fracassados na vida, dentre eles ladrões, prostitutas. Para o historiador, a obra de Górki é um protesto contra as relações burguesas,contra a opressão do homem pelo homem. "Não se tratava da primeira andorinha, mas do primeiro pássaro anunciador das tormentas que se aproximavam” na sociedade russa, daí seu caráter de percussor.

\section{Os três vagabundos de Górki}

Após essa rápida explanação sobre a construção literária do bossiak gorkiano, passaremos rapidamente a analisar as três novelas do autor nas quais o vagabundo é protagonista.

\section{Malva (1897)}

A primeira é a narrativa Malva, um dos primeiros exercícios literários de Górki, publicado em 1897.

Malva é uma prostituta que semanalmente visita o pescador Basílio Legostev. Basílio é um camponês que abandonou a vida rural, deixando para trás a mulher e o filho Iakov. Basílio vive a beira-mar, solitário, trabalhando na pesca para o patrão Grebentchicov. 
Tudo muda na vida de Basílio quando de repente na barca que semanalmente traz a prostituta ele encontra a presença do filho Iakov. Assim como o pai, Iakov sai do campo e vai para a cidade fugindo do trabalho pesado. Rapidamente se forma um triângulo amoroso entre o filho, a prostituta e o pai. As relações familiares já não são das melhores e com a disputa da mulher pelos dois homens a coisa vai ficar pior. E a atuação de Serejka, vagabundo conhecido de Basílio, que juntamente com a prostituta Malva, engana pai e filho.

Destaca-se na narrativa Malva o conjunto de tensões e polaridades: cidade e campo, vagabundos e camponeses, pai e filho etc. A personagem Malva é quem transita entre estas polaridades, sempre afirmando a sua liberdade afetiva, pois não se liga nem ao pai nem ao filho. "Sou livre como uma gaivota. Vou para onde me apetece e ninguém tem direito de me tocar" (p.35), afirma a protagonista em certo momento da novela.

O conflito entre campo e cidade se dá através do conflito pai e filho. O filho culpa o pai pelo abandono da mãe no campo. A cidade é palco das tentações e Malva é a principal delas. $\mathrm{O}$ ex-aldeão tenta convencer seu filho a voltar ao campo. E o filho contraria o pai afirmando que vai ficar na cidade porque "aqui não há fome e o trabalho fatiga menos" (p34). Por fim, o conflito ameaça beirar a violência física, ou seja, o pai vai bater no filho. E o filho esbraveja com razão: "Não me toques, olha que não estamos na aldeia! (...) Aqui todos somos iguais. Eu sou um operário e tu és outro" (p.67).

A grande afirmação da novela Malva é a liberdade. O pai rompe com o campo e a família em busca de uma vida mais fácil fora da aldeia. O filho sai em busca de uma liberdade que também não encontraria no meio rural. Os laços entre pai e filho de certa maneira se desfazem com o conflito. Malva é o ápice dessa afirmação de liberdade. Ela é sempre comparada com uma gaivota. "Malva balanceava como uma gaivota á flor das ondas" (p.43).

\section{Tchelkache}

A história se passa no porto de Odessa, mesmo lugar onde Górki trabalhou realmente como estivador. A protagonista da história é um velho vagabundo e ladrão chamado Tchelkache. Em busca de um comparsa que o ajudasse a roubar seda nos navios durante a madrugada, ele tenta se aproveitar da "ingenuidade" camponesa do ajudante Gravilo. Este é uma das narrativas mais dostoievskianas da primeira fase de Gorki. 
O cenário do porto de Odessa é descrito como um ambiente que oprime os homens, que os desumaniza:

O granito, o ferro, as barcas e os homens, aglomeração imensa de vida e labor, erguem como que um hino sagrado, ao deus do Tráfego. Mas neste brouhaka confuso, as vozes dos homens são afogadas por todos outros ruídos, e eles próprios se sentem pequenos e nulos diante da grandeza imponente que os rodeia.Cobertos de farrapos, curvados sob as cargas enormes, agitam-se como vermes numa atmosfera abrasada e irrespirável, humilhados na sua insignificância, ao lado dos colossos de ferro, das montanhas de mercadorias, dos comboios que correm vertiginosamente, de todas essas coisas, enfim,feitas de pequeninos nadas que as suas mãos ajuntaram num todo uniforme e vivo. A sua obra escraviza-os, anula-lhes a personalidade." (p. 82)

Mais uma vez encontramos na narrativa gorkiana o conflito entre cidade (Tchelkache) e campo (Gravilo) expresso através dos seus personagens. O velho ladrão Tchelkache alicia o camponês ganancioso Gravilo para um roubo bem sucedido no porto de Odessa. Na hora da divisão do dinheiro da venda da seda roubada, o camponês mata o velho ladrão com uma pedrada na cabeça. Grinchka Tchelkache é apresentado como "um sujeito constantemente perseguido pela polícia, famoso como bebedor emérito e gatuno incorrigível" (p.83). Já Gravilo é uma espécie de néscio, que serve apenas para remar o barco a fim de que Tchelkache. Ele é apresentado como "largo de ombros, forte e arruivado, com o rosto marcado pelas intempéries (...) com seus olhos azuis, onde havia uma comunicativa expressão de bondade.” (p.86).

\section{Konovalov}

É nesta última narrativa que o escritor russo aparece como o personagem Máximo, que trabalha numa padaria, como ajudante de amassador. É sabido que Górki escreveu sua autobiografia em três tomos, a maioria deles no exílio ou nas suas viagens ao exterior. Os livros Infância (1913), Ganhando meu pão (1924) e Minhas Universidades (1925) compõe uma trilogia que é um vasto painel do contexto russo e da vida de um dos seus principais escritores. Assim, a narrativa nasce da memória e da vivência das realidades sentidas pelo escritor russo. 
A leitura de uma notícia de jornal, que narra o suicídio de um vagabundo numa prisão russa, vai levar Máximo a relembrar sua amizade com o padeiro Konovalov. Máximo vai consolidar o vínculo com o amigo através da escrita e da leitura, pois ajuda a Konovalov a escrever cartas e lê romances para o companheiro. O interessante é que a narrativa gorkiana vai explorar a dicotomia oral/ escrito, saber formal/saber popular até o extremo, chegando a fazer uma espécie de revisão de toda a literatura russa da época, já que Máximo lê romances para Konovalov nos intervalos ou nas folgas.

\section{Os três malandros sonados de João Antônio}

Objeto de várias teses e dissertações defendidas recentemente em universidades como a Unesp/Assis e USP, o livro Malagueta, Perus e Bacanaço (1963), de João Antônio constitui um marco na literatura brasileira. Pela primeira vez os malandros da sinuca paulista estão representados literariamente como afirma o também escritor Mário da Silva Brito, na primeira edição do livro.

Em torno de Malagueta, Perus e Bacanaço livro de estréia do escritor publicado pela Civilização Brasileira nos conturbados anos 60, correm várias histórias. A primeira dela é que os originais do livro foram destruídos por conta de um incêndio que reduziu a pó a casa do escritor. Conta-se que bastante abalado com o ocorrido, João Antônio, com ajuda de amigos que conseguiram uma cabine para que ele trabalhasse à noite na Biblioteca Mário de Andrade, em São Paulo, reescreveu de cabeça todo o livro.

Verdade ou não, é certo que João Antõnio construiu sua carreira literária e jornalística a partir do sucesso do livro de estréia, um verdadeiro marco na contística nacional. Depois da publicação de Malagueta,Perus e Bacanaço as portas dos principais jornais e revistas se abriram para o paulista.

O livro está dividido em três grandes grupos de contos: contos gerais, caserna e sinuca. Os malandros Malagueta, Perus e Bacanaço aparecem no último conto do último grupo. Por sinal, trata-se do conto mais longo do livro, considerado hoje como um dos clássicos modernos da prosa nacional ao lado de Frio e Paulinho perna torta.

A figura do malandro no conto Malagueta, Perus e Bacanaço é construída sem retoques. $\mathrm{O}$ universo social em que os malandros estão encravados é muito específico e João Antônio conseguiu como ninguém retratar tal cultura, tal modo de vida. Como grupo social, ou melhor, como extrato de um grupo social, o malandro é também um excluído no sistema capitalista. Só que seu "trabalho" é diferente, seu "batente" é outro, é específico. 
Os trabalhadores em geral estão colocados no mercado de trabalho, fazem parte das engrenagens que movem o chamado sistema de produção de riquezas. Eles vendem a força de trabalho em troca de um salário (irrisório) e possibilitam uma mais valia ao patrão, à empresa. Já o malandro é a figura não se encaixada no mercado de trabalho formal ou informal, por motivos variados, tendo que desenvolver estratégias de sobrevivência ( roubo, golpes em otários, jogo, contravenção etc.).

Ao negar o sistema de trabalho assalariado, o malandro nega a sociedade como um todo: suas regras, seus códigos de distribuição de renda, entre outras coisas. E, a partir da construção de um modo de vida específico, ele se coloca fora das regras, fora da lógica do mercado. Seu "trabalho" é diferente, consiste na tentativa de sobreviver a partir da esperteza, de modos de vida considerados fora da norma, portanto perseguidos pela polícia e pela Lei.

Ao tentarem se safar das atribulações, os malandros criam éticas próprias e uma cultura própria de grupo. Assim, João Antônio, ao longo de sua obra literária, soube com muita fidelidade traçar um perfil do malandro brasileiro, não se rendendo a uma ideologia do "malandro cordial", do "bom malandro", do "malandro estilizado" entre outros rótulos domesticadores.

Numa pequena entrevista de apoio, publicada na edição escolar do conto, o escritor João Antônio afirma que "Malagueta, Perus e Bacanaço é simplesmente uma aventura noturna que cansei [ele] de viver logo quando saí do quartel, e que consistia em tentar arranjar algum dinheiro em andanças pelos salões de sinuca. Isso, em geral, era feito pelas últimas horas da tarde, entrando pela noite e madrugada"1.

De fato, se observarmos ainda melhor, nota-se que a aventura tem um roteiro circular. Os malandros partem da Lapa, nas primeiras horas da noite, depois passam por Água Branca, Barra Funda, Cidade, Pinheiros e finalmente retornam à Lapa, nas primeiras horas do dia seguinte. É nesse itinerário, que João Antônio vai nos mostrar as mais variadas situações e também os mais variados tipos humanos que "habitam" à noite, as frias madrugadas.

O espaço, enquanto categoria serve ao escritor João Antônio para fazer o encontro entre os malandros e os otários. É no fim de tarde e começo da noite que os operários saem do trabalho e se dirigem às suas residências. É nesse horário também

\footnotetext{
${ }^{1}$ ANTÔNIO, João.Malagueta, Perus e Bacanaço . São Paulo: Editora Ática: 1987
} 
que os malandros iniciam as suas aventuras nas ruas. A casa e a rua-categorias usadas pelo antropólogo Roberto DaMatta para entender o sistema de relações do Brasil.

Perus, Bacanaço e Malagueta- nessa ordem- o jovem, o homem maduro e o velho. Com isso, João Antônio quis sintetizar as três fases da vida, três momentos, três depoimentos sobre a vida no submundo do sistema capitalista. E o itinerário desses três é circular - ou seja- saem da Lapa e para lá retornam. Nos primeiros jogos (em Água Branca), eles conseguem arrancar mais de três mil em dinheiro das mesas, dos otários. Só que em seguida, em outras duas "estações", eles são pilhados por policiais e também são golpeados por outro malandro mais esperto, Robertinho Chegando à Lapa, cansados, sem dinheiro e com sono, eles estão em situação igual a que sairam:“A curriola formada no velho Celestino contava casos que lembravam nomes de parceirinhos.Falou-se naquela manhã por ali passaram três malandros, murchos, sonados, pedindo três cafés fiados",2

No conto de João Antônio que nós nos detemos na análise, há sempre uma constante referência, até certo ponto fatalista e pessimista, em relação ao destino da malandragem ${ }^{3}$. Tanto no desfecho da narrativa, quanto em discursos das próprias personagens, percebe-se isso.

Mesmo sendo muito esperto, desenvolvendo suas estratégias para a sobrevivência diária (engodo, roubo jogo etc.), o malandro sempre será um excluído, alvo da exclusão. Não estando alinhado à produção nem aos mecanismos do capitalismo ele sempre será perseguido pela ordem. Um exemplo disso é o encontro dos três malandros com o velho inspetor Lima, também jogador, nas mesas do Joana d'Arc, em Água Branca. Policial aposentado, Lima veste um pijama e é assíduo freqüentador dos ambientes de jogo. Lá ele dá "lições" para alguns estudantes/otários sobre a malandragem e o jogo:

Tudo aqui é passageiro-arrotava. - Não é expediente de gente que se preze. Gente moça namora noiva e casa. É o caminho certo. Aqui não; aqui é o fim. (...) Habitante daqui é futuro residente da Casa de

\footnotetext{
${ }^{2}$ ANTÔNIO, João- Malagueta, Perus e Bacanaço. São Paulo: Editora Ática: 1987.

${ }^{3}$ É interessante também notar que SILVERMAN(1981:67) também nota tal fato e relaciona-o com a categoria do espaço. Veremos também, mas na frente desse ensaio, que isso também ocorre com relação ao tempo da narrativa
} 
Detenção (...) ou do Hospício (...) a maior malandragem, meus filhos, é a honesta (p. 27 -28).

Um dos melhores momentos de João Antônio é quando ele compara o inspetor aposentado Lima com o velho malandro jogador Malagueta:

\begin{abstract}
Não era um malandro, nem era um velho coió. Nem era um velho acordado como Malagueta e outros, sem aposentadoria, sem chinelos, sem pijama, sem quarto onde pousar e que têm de seu a cara e a vontade. Enfrentam as virações e a polícia porque têm fome. E vão como viradores, sofredores, pés-de-chinelo. E só. (p.28) ${ }^{4}$
\end{abstract}

Mais na frente, ao longo da narrativa a personagem Malagueta será comparada a um cachorro de rua. Velho jogador, Malagueta não tinha nenhuma garantia, nenhum direito como o inspetor aposentado Lima. A sua condição social é igualada a de um cachorro:

\footnotetext{
Veio o vira-lata pela rua de terra. Diante do velho parou, empinou o focinho, de olhos tranqüilos esperava algum movimento de Malagueta (...) O velho olhando o cachorro. Engraçado-também ele era um virador. Um sofredor, um pé-de-chinelo, como o cachorro. (...) Vida torta, tortinha, feito vida de cachorro escorraçado (p. 38 e $39)^{5}$
}

Devemos salientar que o jogo de sinuca no conto de João Antônio é metáfora da vida. As personagens constroem uma auto-imagem de ganhadoras só que ao final da narrativa elas perderam todo o dinheiro. Malagueta, Perus e Bacanaço são quase que forçados pelo processo de marginalização econômica a tentarem mudar de vida nas mesas de jogo. No entanto, mesmo tendo desenvolvidas várias habilidades técnicas são enganados por um malandro mais esperto, Robertinho. Quem faz esta comparação entre o jogo e a sociedade é o próprio João Antônio em outro livro: "Então a sinuca é uma cópia da sociedade (...) é a própria síntese do patético da vida, da dramaticidade, da luta." 6

\footnotetext{
${ }^{4}$ Idem

${ }^{5}$ Ibidem

${ }^{6}$ ANTÔNIO, João- Casa de Loucos. Rio de Janeiro: Editora Civilização Brasileira: 1976
} 
Ao atravessarem a cidade de São Paulo, durante a madrugada, os três malandros encontram com os mais variados tipos da noite. Prostitutas, jogadores de sinuca, donos de bar, travestis, detetives aposentados, policiais corruptos - estes são algumas personagens que aparecem na narrativa Malagueta, Perus e Bacanaço.

Como um movimento de uma câmera, em panorâmica, o escritor nos mostra o cotidiano da noite/madrugada paulista. E quem conduz os leitores são três tipos característicos desse cenário: os jogadores de sinuca Malagueta, Perus e Bacanaço. Ao avançarem, de mesa em mesa, de bar e bar, em busca de sucesso nos jogos, os três "espertos" vão se deparando com toda a "fauna" do submundo.

Um dos aspectos do longo conto de João Antônio que se deve reparar é como ele representa a chamada dialética entre ordem/desordem, entre lei e infração. Para tanto, ele se vale da figura dos protagonistas, três jogadores de sinuca para lá de malandros, que aprontam tudo em busca da sobrevivência. A marginalidade é como que justificada pela busca da sobrevivência. Os três homens se metem nas mais variadas enrascadas em busca do cotidiano sustento e não de diversão como se pensa. $\mathrm{O}$ tom da narrativa é meio que fatalista. Eles têm que se jogar na "viração" porque é dessa forma que eles se mantêm.

\section{Aproximações entre Górki e João Antônio}

Os vagabundos nas narrativas de Máximo Górki podem ser caracterizados por alguns traços constantes, são eles: primeiro, a vida errante; segundo, em consequiência dessa vida errante, uma apologia à liberdade do vagabundo por conta do seu desprendimento expresso através do uso de imagens recorrentes de pássaros; a repulsa das relações sociais concretizada através da negação da vida urbana e ao mesmo tempo do mundo servil e rural do camponês; a alternância entre o trabalho ocasional, a mendicância ou o roubo de acordo com a situação.

Nas três narrativas gorkianas o gosto pela liberdade está mais para a doutrina libertária do que para o socialismo. Máximo Górki nos mostra que os vagabundos têm o gosto pela liberdade em todos os aspectos: o amoroso (negação da família e do casamento), o laboral ( contra o trabalho rude dos campesinos) e contra as leis. A autoexclusão dos vagabundos determina ainda uma outra série de conseqüências: o acesso ao poético através de um estoicismo radical, uma poética de relação direta com a 
natureza, já que os vagabundos estão mais expostos aos caprichos da natureza; por fim, o senso de coletividade, de cooperação jamais observado na sociedade capitalista.

Em João Antônio a malandragem é parte do ambiente urbano e ao mesmo tempo vítima dele. A deambulação é fundamental para a sobrevivência dos malandros, numa odisséia às avessas, numa via crucis circular que vai nos mostrando a humanidade das personagens. Como continuador de uma tradição realista universal, João Antônio traz ao conto brasileiro camadas jamais representadas anteriormente: os jogadores de sinuca. $\mathrm{O}$ universo lingüístico e simbólico de Malagueta, Perus e Bacanaço coloca o conto numa posição de grande valor na história recente da literatura brasileira.

\section{REFERÊNCIAS}

ANTÔNIO, João. Malagueta, Perus e Bacanaço. São Paulo: Civilização Brasileira,1963 ( Coleção Vera Cruz)

AZEVEDO FILHO, Carlos Alberto Farias de. João Antônio, repórter de Realidade. João Pessoa: Idéia, 2000.

BRÜCKNER, Alexander. Historia de la literatura rusa. Tradução de Manuel de Montolin. Barcelona: Labor, 1929 (Coleccíon Labor n 207-208)

GORKI, Máximo. Contos. Seleção, tradução, prefácio e notas de Boris Schnaiderman. Rio de Janeiro: Philobiblion, 1984 (coleção Prosa Estrangeira, 1)

Como aprendi a escrever. Tradução e prefácio de Charles Kiefer. Porto Alegre: Mercado Aberto, 1984.

Os vagabundos.Malva- Tchelkache- Konovalov.Tradução de Araújo Alves. Rio de Janeiro: Edições de Ouro, 1965 (Coleção Clássicos de Bolso,1195)

Os degenerados. Tradução de Mário Jobinski. Rio de Janeiro: Edições de Ouro, 1965 (Coleção Clássicos de Bolso,467)

. As minhas universidades. Tradução de Paulo Rodrigues. Rio de Janeiro: Edições de Ouro, 1965 (Coleção Universidade de Bolso).

. Ganhando meu pão. Tradução e apresentação Boris Schaiderman São Paulo: Brasiliense, 1986.

—. Vagabundo Original. Tradução Torrieri Guimarães. São Paulo: Livraria Exposição do Livro, 1964

ORNELAS, Clara Ávila. O conto na obra de João Antônio: uma poética da exclusão. São Paulo: Universidade de São Paulo( USP),2004 (Tese de Doutorado) 